\title{
A CrianÇa Celestial: PeRAmbulaÇões entre Aruanda E O INCONSCIENTE COLETIVO ${ }^{\star}$
}

\author{
Júlia Ritez Martins $\star \star$ \\ José F. M. H. Bairrãoo $o^{\star \star}$
}

\begin{abstract}
RESUMO
Tendo em vista que a religião umbandista expressa e explicita etnoteorias psicológicas afro-brasileiras, esta pesquisa visou explicitar os sentidos associados a sua concepção do infantil, mediante o estudo de um dos principais personagens do seu panteão, os espiritos de crianças. Para efeito de contraste e no intuito de auxiliar a organizar as concepções umbandistas, tomou-se como referência a psicologia junguiana. Combinou-se a observação participante com a realização de entrevistas com praticantes da religião e com médiuns em transe de espíritos infantis. Observou-se que esses espíritos revelam-se principalmente por formas não verbais de comunicação. As aproximações no plano da significação entre o arquétipo do puer e a manifestação espiritual de crianças na umbanda devem ser feitas com cuidado e a assimilação destas àquele só pode ser feita mediante uma sobreposição de uma concepção de psíquico a uma etnoteoria diversa.
\end{abstract}

Palavras-chave: etnopsicologia; psicologia junguiana, umbanda; puer; criança.

The CELESTIAL CHILd: PERAMBULATIONS BETWEEN ARUANDA AND THE COLLECTIVE UNCONSCIOUS

\begin{abstract}
Considering that Umbanda religion expresses and elucidates Afro-Brazilian psychological ethnotheories, the aim of this research was eliciting the meanings connected to its concept of infant by investigating one of its pantheon main characters, the spirits of children. Jungian psychology was taken as reference not only for a contrast effect but also to facilitate Umbanda concepts organization. Both participant observation and interviews with worshippers and mediums in

\footnotetext{
^Agências de financiamento: CNPq/PIBIC; FAPESP

$\star \star$ Psicóloga. Mestranda do Programa de Pós-Graduação em Psicologia da Faculdade de Filosofia Ciências e Letras de Ribeirão Preto - USP. Endereço: Universidade de São Paulo - Avenida Bandeirantes, n. 3900 - Monte Alegre. Ribeirao Preto, SP - Brasil. CEP: 14040-900.

E-mail: juliaritez@gmail.com Preto - USP. Endereço: Universidade de São Paulo, Faculdade de Filosofia Ciências e Letras de Ribeirão Preto, Departamento de Psicologia e Educação. Av. Bandeirantes, 3900 (Bloco D sala 7) - Monte Alegre. Ribeirao Preto, SP - Brasil. CEP: 14040-901.

E-mail: jfbairrao@ffclrp.usp.br
}

$\star \star \star$ Psicólogo e fisósofo. Professor Doutor da Faculdade de Filosofia Ciências e Letras de Ribeirão
\end{abstract}


trance receiving children's spirits were performed. It was shown that these spirits reveal themselves by using mainly non-verbal ways of communication. As far as meaning is concerned, drawing the puer archetype near children's spiritual manifestation in Umbanda deserves careful approach, and assimilating these children into the archetype can only be performed by the superposition of a psychic concept on a diverse ethnotheory.

Keywords: ethnopsychology; jungian analysis; umbanda; puer; child.

\section{INTRODUÇÃO}

Apesar de ser vista como uma das mais importantes categorias do panteão umbandista, são escassos os estudos científicos a respeito da classe de espíritos infantis na umbanda. Neste artigo relatam-se resultados de pesquisa cujo objetivo foi compreender os sentidos dos espíritos de crianças com base no modo como eles se apresentam na interação com os consulentes, médiuns e pesquisadores no intuito de proceder a um levantamento etnopsicológico da concepção umbandista do infantil. Os resultados encontrados foram contrastados com concepções junguianas.

O enfoque etnopsicológico tem entre os seus pilares a valorização do saber do outro e o considera sem o estabelecimento a priori de relações de hierarquia entre ele e teorias científicas psicológicas. Segundo Lutz (1985), essa disciplina se preocupa com a maneira como as pessoas conceituam e discutem os processos mentais, comportamentos e relacionamentos; por meio, principalmente, da investigação etnográfica da linguagem.

A umbanda possui uma singular e rica concepção de pessoa e mundo, constituindo-se como solo fértil a ser explorado etnopsicologicamente. De acordo com Lima (1997), trata-se de um fenômeno religioso e social, fruto das culturas negra, ameríndia e europeia, que guarda memórias sociais e se estende a todo território brasileiro, penetrando as diversas classes sociais e participando intensa e profundamente das vidas psíquicas dos praticantes. Durante o ritual são incorporadas diversas entidades que auxiliam os adeptos, através de conselhos, passes etc., em diferentes questões, tais como aquelas financeiras, de relacionamento, de doenças, entre outras. Acredita-se que esses espíritos habitam um reino mítico conhecido como Aruanda, denominação derivada de Luanda, capital de Angola, relacionada com as origens africanas do culto. Nesse contexto, a classe dos espíritos infantis é sincretizada com o orixá africano Ibêji, crianças gêmeas, e os santos católicos, também gêmeos, Cosme e Damião.

As características que se repetem nos rituais em que essa entidade se faz presente são principalmente a alegria que envolve os participantes do culto, o fato de esses espíritos apreciarem brincadeiras, doces e guaranás, e o tratamento aos demais por tio e tia. Segundo Bairrão (2003), além de associada à alegria, esta linha também expressaria uma interpretação umbandista de inocência e de pureza. 
Para Campelo (2003, p. 82), os espíritos de crianças “introduzem na vida cotidiana uma catarse, dando aos iniciados - os médiuns - a possibilidade de reviverem uma infância idealizada, em oposição aos conflitos e problemas reais que o adepto tenha passado em sua infância".

Em congruência com esta visão, Lima (1997) classifica esses espíritos como entidades desrepressoras, por permitirem aos indivíduos, durante a possessão, expandirem fantasias que estavam contidas e a irrupção de aspectos do inconsciente reprimidos, sendo a extroversão característica comum desse tipo de manifestação.

Bairrão (2004, p. 210) levanta a hipótese de que os espíritos de crianças na umbanda seriam 'uma dramatização do próprio espírito, do 'self', tal como realmente se encontra, não realizado, numa espécie de limbo”. Também para Zacharias (1998) a linha das crianças se relacionaria à possibilidade do novo e ao self, que tem na figura da criança divina uma de suas imagens.

Por último, Birman (1985) relatou ser a linha dos pretos-velhos a mais próxima dos espíritos de crianças, por ambos dependerem dos adultos, brancos. Porém, de acordo com a autora, as crianças não são humildes como os pretosvelhos, pelo contrário, segundo ela apresentam-se exigentes e autoritárias. E, por oposição aos adultos, os espíritos de crianças ainda não possuiriam senso de moral ou de responsabilidade. "Mas, por outro lado, o fato de serem crianças dá a esses espíritos um poder de limpeza particular. Terminar a gira com crianças é uma forma de afastar espíritos muito atrasados, como os obsessores e todas as vibrações negativas" (BIRMAN, 1985, p. 44).

Para efeito de contraste e rastreamento de possíveis relações entre a cosmovisão umbandista e uma concepção acadêmica sobre o infantil, a pesquisa se apoiou nas teorias de inspiração junguiana sobre o simbolismo da criança.

Cabe assinalar que, neste estudo, foi adotada a concepção de símbolo enquanto detentor de inúmeras possibilidades, porém com o cuidado de não pressupor o contexto umbandista e as entidades de seu panteão como meros efeitos dessa manifestação simbólica.

Para tanto, recorreu-se a Zacharias (1998) que procurou igualmente não reduzir seu objeto de estudo a teorias psicológicas, afirmando que "um orixá é uma potencialidade psíquica, ao mesmo tempo em que é uma divindade" (ZACHARIAS, 1998, p. 12). No entanto, há ainda muito a ser explorado nesta direção, posto que seria preciso aprofundar essa ideia e explicitar conceitualmente como se articularia esta dupla pertença, sendo que esta pesquisa não teve o intuito de debater tal questão.

A escolha da abordagem junguiana para efeito de contraposição à cosmovisão umbandista também se justifica pelo fato de ter sido bastante utilizada em pesquisas sobre as religiões afro-brasileiras (FERNANDES, 2007; LAGES, 2007; LIMA, 1997; SEGATO, 1995; SILVA, 2000; ZACHARIAS, 1998). Além disso, ela disponibiliza uma concepção do infantil, que se infere das suas asserções a respeito do arquétipo da criança. 


\section{A psicologia analítica}

Nessa perspectiva tem-se a ampla utilização do conceito de arquétipo que seria um conteúdo inconsciente, segundo Jung (2000, p. 17) "o qual se modifica através de sua conscientização e percepção, assumindo matizes que variam de acordo com a consciência individual na qual se manifesta". Para Hillman (1981), o arquétipo é o princípio organizador das imagens, que proporciona à realidade psíquica seus padrões típicos. Além disso, o arquétipo também é visto como parcialmente indefinível e transcendente à psique.

$\mathrm{O}$ arquétipo da criança, que pode ser denominado também como puer, de acordo com Hillman (1998), aparece pela primeira vez na obra de Jung em 1912 e é retomado por ele e outros muitas vezes desde então. Dentre os autores que exploraram esse tema, destaca-se ainda Marie-Louise Von Franz. Apesar de haver uma discussão maior sobre esse arquétipo, trata-se de um tema de difícil compreensão, uma vez que ele tende a unificar a criança, o herói, o divino, o messias, o filho da grande mãe, etc. em um só arquétipo.

Segundo Von Franz (1992), o deus-criança da Antiguidade, conhecido como puer aeternus (juventude eterna), é o deus da vida, da morte, da ressurreição e veio ao mundo para ser o redentor. A criança representa a possibilidade de renovação e o fluir na vida, associação que decorre de suas características intrínsecas, como a inocência e o fato de se apresentar constantemente cheia de vida. Acrescenta ainda que a criança é um símbolo de união. Ela integra as partes dissociadas da personalidade.

A principal contribuição dessa autora, com relação a esse tema, diz respeito à questão psicopatológica. Nesse caso, ela utilizará a denominação puer aeternus para se referir ao indivíduo com um complexo materno incomum e que, por conseguinte, apresenta um comportamento característico. Tal comportamento inclui, segundo ela, o fato de parecerem eternos adolescentes dependentes da mãe, imaturos afetivamente, possuírem complexo de Don Juan, individualismo social, egocentrismo exarcebado, desadaptação social, etc. (VON FRANZ, 1992).

Jung (2000) propôs que algumas das categorias da vivência e compreensão do arquétipo da criança são: a mutabilidade, a futuridade, a função de unir os opostos, o impulso de autorrealização, a invencibilidade heroica e divina, o começo e o fim, a ausência de relação com a consciência, o motivo do abandono e o hermafroditismo.

Com relação à mutabilidade, Jung (2000, p. 161) diz que "o motivo da criança é extremamente mutável, assumindo todos os tipos de formas possíveis, pedra preciosa, pérola, flor, vaso, ovo dourado, quaternidade, esfera de ouro, etc. Pode ser intercambiada com essas imagens e outras".

Portanto, a criança concreta seria apenas uma das possíveis imagens desse arquétipo. 
Já o caráter futuro do arquétipo do puer se dá em função de a criança ser o futuro em potencial. Ela pode significar, no processo de individuação, a transformação da personalidade, por meio da síntese de aspectos conscientes e inconscientes. Em função disso é comum figuras de crianças representarem salvadores míticos, pois a função desse arquétipo é justamente unir os opostos, ser um mediador que propicia a completude, ser um "portador da salvação" (JUNG, 2000).

Em outras palavras, ocorre que a consciência por vezes se encontra dilacerada pelos opostos, situação que configura um conflito aparentemente sem saída. E , de acordo com Jung (2000, p. 168), "desta colisão dos opostos a psique inconsciente sempre cria uma terceira instância de natureza irracional, inesperada e incompreensível para a consciência".

Dessa forma, todos os símbolos unificadores, ainda que imprescindíveis, são desconhecidos pela consciência, que não é capaz de reconhecer aquilo que une os opostos, ainda que tenha um efeito fundamental e fascinante sobre a mesma. Por isso, uma das características desse arquétipo, destacada por Jung (2000), é o fato de a criança ser "insignificante" e desconhecida por um lado, e divina, invencível, por outro.

Além disso, este arquétipo é considerado por Jung (2000) como a personificação de forças vitais, representando o mais forte impulso do ser, aquele que busca realizar-se a si mesmo. Essa compulsão para a autorrealização seria uma força invencível. Daí provém a invencibilidade e o poder da criança.

O motivo da criança ainda alterna entre aspectos divinos e heroicos. A divindade está relacionada ao self, ${ }^{1}$ pois a imagem de Deus, segundo Jung (2000), pode ser vista como uma personificação do inconsciente coletivo não integrada ainda em um ser humano. E o herói, enquanto ser semidivino, representa a síntese do self e da consciência humana. Assim, reforça-se o significado da criança como sendo "uma antecipação potencial de uma individuação que se aproxima da totalidade" (JUNG, 2000, p. 167).

Logo, a criança estaria a um só tempo associada ao self, à totalidade, sendo o ser do começo e do fim, e seria ainda a antecipação desse estado. Esse arquétipo se relacionaria ainda ao impulso de realização do self. Pode-se dizer que seria como se no processo de individuação o self fosse ao mesmo tempo o ponto de partida e a meta da sua consumação e a criança estaria relacionada a esses dois momentos.

Em suma, o arquétipo da criança cumpriria a função de integrar aspectos conscientes e inconscientes, trazendo a renovação, solução de conflitos e proporcionando a autorrealização, sem que este motivo seja percebido pela consciência. $\mathrm{O}$ desenvolvimento rumo à autonomia é possível por meio do desligamento da origem, sendo o símbolo da criança relacionado à antecipação de um estado nascente de consciência (JUNG, 2000, p. 169). 
Por último, a característica hermafrodita da criança, na visão de Jung (2000), vem ressaltar sua função enquanto arquétipo, pois esse símbolo significa a união dos opostos. É um símbolo possibilitador da resolução de conflitos. Isto decorre do fato da totalidade humana poder ser constituída através de uma união dos aspectos femininos (anima) e dos masculinos (animus) inconscientes.

Já para Hillman (1998), a caracterização do puer como sendo hermafrodita vem da relação entre os arquétipos senex e puer, pois enquanto o primeiro ganha a perfeição com o passar do tempo, o último seria essencialmente perfeito. Dessa forma, pode-se dizer que para o arquétipo infantil não há evolução e nem necessidade do outro, do feminino, conforme Jung propôs. Ele estaria relacionado à totalidade.

Nesse sentido, conforme foi dito anteriormente, a criança pode simbolizar o próprio self. De acordo com Hillman (1998), o arquétipo do puer é o responsável por transmitir o sentido, destino e missão, sendo que dentro de cada complexo ou atitude ele é o chamado para o próprio self, para se tornar verdadeiro consigo mesmo, permitindo uma conexão direta com o espírito.

Esse autor afirma ainda que o puer é o oposto da psique. Seria o arquétipo menos psicológico, o mais distante da alma (anima), fantasias, imagens, etc. Dessa maneira, tratar-se-ia de arquétipo associado ao espírito, ao elevado, ao self. E quando ele atua em um complexo, segundo Hillman (1998), não permite a reflexão, mas faz com que haja movimento.

Para Hillman (et al, 1979), o puer está emparelhado principalmente com a figura do senex (velho), tendo o arquétipo materno um valor secundário. Ele diz que o senex é a imagem da história em si, enquanto o primeiro a transcende, está fora do tempo e, portanto, estão intimamente associados ao tempo como processo (Hillman, 1998). Tais arquétipos estariam envolvidos com o aspecto de processo de qualquer complexo e ligados ao desenvolvimento. Além disso, podem aparecer em qualquer estágio, pois a vida psicológica não está submetida às condições biológicas.

Os arquétipos senex e puer não seriam dois, mas apenas um com algumas diferenciações, o senex-et-puer. Acrescenta que a relação senex-et-puer seria fundamental e responsável por propiciar ao ego a força criadora ou "significação de espírito", sendo que, se essa dualidade é cindida, tem-se a prevalência do aspecto negativo do arquétipo. Isto é, sem a criança, resta apenas o conhecimento depressivo e sem o senex, projeta-se a loucura e imaturidade nos outros (Hillman, 1998).

Nesse sentido, Jung enfatiza ser da natureza dos arquétipos as interpenetrações recíprocas e fluidas. Isto é, não seria possível tratar de um determinado arquétipo de forma isolada, já que ocorre um entrelaçamento entre os arquétipos. Assim, esse autor também apresenta a criança e o velho como pertencendo um ao outro. O infantil, por exemplo, estando ligado ao espírito, teria relação com o arquétipo do espírito, muitas vezes representado por um menino, ou por um velho sábio (JUNG, 2000). 


\section{MÉTOdo}

A pesquisa de campo se deu primordialmente em dois terreiros de umbanda, localizados em Rio Claro (Templo de Umbanda Caboclo Trovão) e em Ribeirão Preto (Terreiro de Umbanda Pai José do Rosário), no período de julho de 2006 a setembro de 2008, tendo sido feitas 18 visitas a cada um deles. A identificação dos terreiros foi realizada com a devida autorização e com o intuito de reconhecer publicamente a sua participação.

$\mathrm{Na}$ coleta de dados, foi utilizado um Termo de Consentimento Livre e Esclarecido e foram combinadas a observação participante com a realização de entrevistas com praticantes da religião e com médiuns em transe de espíritos infantis. Manteve-se em suspenso o juízo de realidade a respeito da existência de espíritos, ou seja, do ponto de vista do modo como o fenômeno se apresenta, entrevistas com os próprios espíritos. A finalidade última da interpretação dos dados etnográficos foi a de resgatar o sentido dos espíritos de crianças na umbanda.

A análise dos dados foi realizada mediante a leitura e releitura das entrevistas e do diário de campo e os sentidos encontrados foram comparados com a literatura sobre os arquétipos. A partir disso, foram identificadas questões associadas aos espíritos infantis que se repetiam e poderiam ser consideradas como típicas dessa classe de entidades. Buscou-se encontrar possíveis pontos de interseção e esclarecer os contrastes.

\section{Resultados E Discussão}

\section{OS ESPÍRITOS DE CRIANÇAS NA UMBANDA E O ARQUÉTIPO DO INFANTIL}

No trabalho de campo a caracterização da criança como uma das figuras de maior importância no panteão umbandista foi unânime. O infantil é apresentado como a "linha de Cosme e Damião" e em alguns terreiros são chamados de erês.

De maneira geral, os espíritos na umbanda são incorporados para proporcionar algum tipo de beneficio àqueles que os procuram. Os consulentes costumam buscar conselhos para as mais diversas questões, palavras de conforto, acolhimento e tomar o "passe", ou se "benzer" durante as "consultas" com essas entidades.

Já os espíritos de crianças demonstraram um comportamento diferente daquele dos demais espíritos, que possuem igualmente um lugar de destaque no panteão umbandista (preto-velho, caboclo, baiano). Primeiramente, eles são incorporados com menor freqüência, geralmente, um vez ao ano, durante as festas de Cosme e Damião.

Nessas festas, todo o terreiro se mobiliza com alegria para a realização dos preparativos. Enfeita-se o terreiro com balões de ar, como em festas infantis, prepara-se uma mesa com bolos e diversos doces e todos 
contribuem para a sua aquisição e auxiliam em sua confecção. A "casa" fica transformada nessas ocasiões. Há muita fartura de comida: doces e bebidas adocicadas (especialmente guaraná).

Quando os espíritos infantis são incorporados, oferecem "consultas" aos adeptos com menor frequência. Com relação a essa forma diferenciada de trabalho, tem-se o seguinte trecho de entrevista:

\section{Então, tia quando tem um trabalho pá fazê, que num precisa ser um trabalho aos olhos docês, né? Achim num precisa ser visto pocês, só de nóis fazê nosso trabalho (Manoel - espírito infantil do terreiro Pai José do Rosário, 24/08/2007).}

Acrescenta-se que, durante o trabalho de campo, as tentativas de aproximação dessas entidades para realização das entrevistas, de maneira mais formal, não foram bem sucedidas. As crianças apenas se "mostravam" no momento em que se "relaxava" e se parava de tentar compreendê-las. Houve, por exemplo, uma entrevista com o mesmo espírito, em que foi perguntado qual seria a melhor forma de entendê-los e a resposta foi a de que: "não era falando mas sentindo, que apesar de não incorporarem com frequência sempre estão por perto para ajudar" (Manoel, 28/09/2007).

Foi constatado, portanto, que a principal maneira do infantil se revelar na umbanda é por meio de formas não verbais (brincadeiras, tônus afetivo, gestos etc.).

Talvez o fato de serem incorporados e oferecerem "consultas" com menor frequência e não poderem ser "alcançados" por técnicas puramente verbais pode ser associado à característica do arquétipo da criança de estar associado ao self, ao espírito, transcendendo a consciência e as fantasias (JUNG, 2000; HILLMAN, 1998).

Além disso, não é comum que se atenham a longas conversas, eles tratam diretamente dos problemas e o fato de se reportarem ao sentir e ao não verbal pode reportar-se ao fato de induzirem diretamente à ação elidindo a reflexão (Hillman, 1998).

Os espíritos infantis se identificaram como crianças que teriam vivido na Terra e tido a oportunidade de "encarnar" por diversas vezes, acelerando sua evolução espiritual. Como consequência disso, seriam entidades de "muita luz".

Segundo Manoel (24/08/2007), essas entidades retornam à Terra cumprindo ordem divina, através da linha de Cosme e Damião, para ajudar aqueles que necessitam: "então se nóis escolhe tabalha tia, nóis tem que tabalha! Falo po meu vô ó, eu escolho tabalha e tô fazendo igual o senhor mando eu faze".

Com base nas entrevistas com os médiuns, igualmente pôde ser estabelecida uma relação entre a linha de Cosme e Damião e o arquétipo da criança no que diz respeito a seu distanciamento da consciência, como ilustra o seguinte trecho:

[...] Difícil colocar uma palavra assim, é... mas a linha das crianças é uma linha que... o eu não sei se você assim já consegue perceber, mas é o trabalho na hora que eles chegam, 
que a gente sabe que tá sentindo, assim que eles chegam, que a gente sabe que eles vão vir, a palavra seria tranquilidade, sabe uma uma, não sei, acho que é tranquilidade, que é... anh... (Médium, 16/04/2007).

Acrescenta-se que a tranquilidade descrita como sendo resultado da influência dos espíritos infantis pode estar relacionada à linha dos pretos- velhos. De acordo com Concone (2001), esses espíritos se relacionariam à calma e à bondade. Ocorre que, durante o ritual em que as crianças são incorporadas, comumente a primeira entidade a ser incorporada é da linha dos pretos-velhos.

Considerando que os espíritos de crianças costumam aparecer nos rituais em que há presença dos pretos-velhos, pode-se dizer que, assim como no caso do arquétipo da criança (HILLMAN, 1998; JUNG, 2000), os espíritos infantis também estariam associados à figura do velho, sendo que na psicologia analítica o arquétipo do velho aparece como complementar ao da criança (HILLMAN, 1998).

Nas entrevistas com os espíritos infantis, a figura do velho também esteve sempre presente. Seja nos relatos de como é o lugar onde vivem ("Aruanda"), em que essas entidades parecem conviver, seja nos "trabalhos" que realizam, os pretos-velhos apareceram sempre orientando a atuação das crianças.

Conforme Birman (1985), as crianças não são humildes como os pretosvelhos. A figura da criança pareceu mais associada a uma figura cheia de caprichos. No entanto, essa característica de às vezes se apresentarem mandonas e manhosas, considerando a convivência com esses espíritos, parece estar mais associada ao riso provocado por essas atitudes, sendo o sentimento peculiar despertado pela linha a alegria. Cabe destacar que o comportamento das entidades infantis, quando se mostravam manhosas, não foi observado pelos participantes do ritual de uma maneira depreciativa.

Quanto à visão da criança enquanto amoral e isenta de responsabilidade (Birman, 1985), observou-se que os espíritos infantis são considerados como sendo entidades com grande conhecimento e responsabilidades.

[...] mas nóis trabalha tia, nóis trabalha pra num tê que volta mais, não purquê nóis num gosta, não porque nóis num qué. É porque tia, nóis caminho batante pá chegá aqui e meu vô ensina nóis que não facha isso [...] (Manoel, 24/08/2007).

Assim como o arquétipo do infantil estaria relacionado ao self(JUNG, 2000), a criança na umbanda, de acordo com seu elevado posicionamento no panteão umbandista, pode ser associada ao espírito, ao elevado, conforme dito anteriormente.

Manoel (24/08/2007) descreveu a linha de Cosme e Damião como a mais próxima de Deus ("vô maior"):

Na realidade assim, ó tia! Todos nóis tá perto do meu vô, né? Do meu vô maior achim, todos nóis, mais nóis tia! Vou fala de uma forma que fica bunito pocê, achim. Nóis é comandado 
dileto do meu vô, porque nóis tá na energia mais póxima de quando volta pra ele, entendeu tia?

Durante essa mesma entrevista foi dito por um dos médiuns que os espíritos de crianças sabem o que devem fazer, qual o caminho a seguir e quais consequências terão; e que se trata de entidades que não sofrem qualquer influência externa e, por isso, são os únicos responsáveis por suas escolhas, enfatizando que possuem o livre arbítrio.

Em contrapartida, o médium afirmou que os encarnados sofrem todo o tipo de influência externa e, por estarem distantes de Deus, recebem sua mensagem de uma forma muito sutil, sendo que os espíritos infantis ajudariam a recuperar o seu sentido. Tal como o puer faz a ligação com o self, eles seriam os responsáveis por reforçar essa mensagem divina:

Médium: [...] como a gente tá tão longe de Deus, essa ordem chega pra nós tão sutil, que a gente invoca que num quer e num faz, depois a gente tem as conseqüências disso.

Manoel: mas nóis rodeia né, tio? [Fala:] faz assim, faz assim que meu vô mandou[...]

Médium: e eles ajudam nisso, falam faz isso que Deus quer que você faça isso [...] (24/08/2007).

Assim, na umbanda como para a psicologia junguiana (HILLMAN, 1998), a criança pode ser considerada como portadora da mensagem espiritual, do divino.

Ela pode ser encarada também como um mediador no processo de autorrealização, relacionado à futuridade (JUNG, 2000). Exemplo disso pôde ser encontrado na fala de Manoel, que, ao ser questionado sobre como seria possível sentir melhor a linha de Cosme e Damião, respondeu: "sendo de verdade com a senhora mesma".

Portanto, para se aproximar e compreender melhor essa categoria de espíritos, segundo os mesmos, é necessário ser autêntico para consigo mesmo, em congruência com Hilman (1998), que, com relação ao arquétipo da criança afirma que o puer é o chamado para o próprio self, para se ser verdadeiro consigo mesmo.

Nesse sentido, outra característica que pareceu marcante desses espíritos foi a de responderem as expectativas dos consulentes, expressas verbalmente ou não, e às vezes antes mesmo da pessoa se dar conta de tal expectativa.

Ainda com relação à futuridade e ao chamado para o self (HILLMAN, 1998; JUNG, 2000), tem-se o exemplo de interação de um dos autores do artigo com essas entidades. Por diversas vezes o jeito que elas encontraram para se revelar foi se remeter diretamente ao interlocutor. Quando se esperava encontrá-los na interação ritual, muitas vezes se apresentaram como responsáveis por mudanças sutis no estado psicológico do observador. Deste modo, o seu estudo requereu grande maleabilidade. 
Além disso, a experiência em campo confirmou que um dos principais significados atribuídos às crianças foi a pureza:

Porque a criança tia [...] a quiança... ela representa a pureza... ela num tem assim... aquela, assim pucê intendê, pega assim um um... tem assim um caminho, a quiança de cincu aninhu, ela num, assim de cincu aninhu... de seis aninhu, de qua, de seis aninhu... ela num tem aque aquela aquela, ela tem a puleza, ela num enxerga a maldade... ela num tem malícia... do que o o o oto mai veio. Então tem coisas, qui as quiança faiz qi os oto num pode faze, purque purque a criança consegue entra... onde o outro mais velho não consegue entra (Sara, espírito infantil do Templo de Umbanda Caboclo Trovão, 05/02/2007).

A forma mais comum de interação entre os espíritos infantis e os demais participantes do culto é por meio de brincadeiras. As crianças costumam presentear "os tios" com brinquedos ou doces e os convidam a brincar.

[...] então as pessoas não vêm atrás deles, a maioria vêm por curiosidade, que eles têm um jeito diferente de falar, eles têm um jeito diferente e legal de agir, que é engraçado, eles falam em graça o tempo todo. Então, as pessoas não vêm buscar aquela consultoria, vêm mais porque é um ambiente gostoso, a conversa acaba acontecendo tranqüilamente. (Médium, 18/04/2008).

Esses espíritos parecem ser capazes de transformar qualquer situação de uma forma lúdica e bem-humorada. Houve, por exemplo, uma gira no Terreiro de Umbanda Pai José do Rosário em que uma das crianças foi conversar com um jovem que tinha sofrido recentemente um acidente grave e perdido quase todos os movimentos do corpo. Apesar de se tratar de um assunto muito difícil de lidar, a entidade conversava sobre o acidente com muito bom humor, brincava com todos ao seu redor e ainda chamava a atenção de um dos chefes do terreiro, fazendo uma expressão mais séria e dizendo que estava no meio de uma consulta e depois sorria.

É possível associar essa característica à mutabilidade do arquétipo infantil, e também ao fato de a criança ser "insignificante" e desconhecida, por um lado, e divina, invencível, por outro (JUNG, 2000).

Considerando as narrativas dos espíritos infantis, destacou-se ainda um aspecto nas histórias apresentadas por eles: o fato de se narrarem como tendo passado por momentos de muitas dificuldades quando vivos, apresentando-se normalmente como crianças pobres e que passaram por necessidades materiais, como no exemplo a seguir:

Eu fiquei dodói tia, eu era assim, eu fiquei dodói [...] e meu pai, minha mãe... não tinha assim condição de tatá eu, sabe? De compá remédio pá mim, aí... eles tataram assim dentro das 
condição deles sabe? Mais o meu o minha dodói, era assim dodói bastante sério, sabe? Que o dinhero, pataco qui eles ganhava, qui eles ganhava num dava pá comprá remédio pá trata o meu dodói, então eu fui embora, por isso fui embora. (Sara, 05/02/2007).

Tal característica pode ser relacionada ao motivo do abandono e do herói do arquétipo infantil (JUNG, 2000), pois ambos estão associados a momentos de exposição a perigos, de maior fragilidade, que podem inclusive levar à morte, possibilitando um posterior renascimento.

Os espíritos infantis, assim como o puer, também podem representar o começo e o fim, pois enquanto crianças se relacionam com o começo, mas como já morreram podem ser associados também ao fim. Dessa maneira, podem compreender-se como atemporais (JUNG, 2000).

Com relação à associação do arquétipo da criança ao hermafroditismo, é possível estabelecer uma relação com o sincretismo de influência africana, pois, de acordo com Augras (1994), o orixá Ibeji, apesar dos traços femininos e masculinos, não possui indicação de uma identidade diferenciada. No entanto, a partir de observação em campo não foi possível estabelecer uma relação com tal característica. Essas entidades se caracterizam como meninos ou como meninas e nas suas "brincadeiras" e atividades o gênero aparece bem definido. Porém não se verificou no que essa variável interfira ou especifique qualquer modalidade da sua competência ritual. Todos brincam e participam igualmente dos mesmos "trabalhos".

\section{O INFANTIL CELESTIAL E SEUS RITUAis}

As crianças foram muitas vezes associadas a "cura", mas esta não apenas relacionada a questões materiais. De acordo com as entrevistas, trata-se de uma "cura espiritual".

Os tio doutor... as tia doutora vão dá tudo remédio e mais os remédio que nóis dá pra eles é as alegriaaa, nóis cuida assim dando levando alegriia... levando, levando flooor, dexando os tio tudo alegre, chabe? Porque quando tão, tão dando risada. Tão contente, eles vão curando, sarando mais rápido (Sara, 05/02/2007).

Além de auxiliarem na obtenção da cura, que foi relacionada a sua característica de promover a alegria, em entrevistas realizadas com médiuns do Terreiro de Umbanda Pai José do Rosário, foi apontado que, embora não haja uma hierarquia com relação à importância das linhas da umbanda, cada uma teria uma função específica, algo que executa com maior facilidade, sendo a linha das crianças a responsável pelas questões mais sutis, ligadas ao espírito:

[..] pela nossa experiência a gente sabe que eles cuida de coisa sutil, é... problema com criança... é doença de criança, é... de repente a criança não tá doente, mas tem alguma coisa 
que perturba ela... sempre quando for alguma coisa relativa à criança, eles sempre vêm na frente (Médium do Terreiro de Umbanda Pai José do Rosário, 24/08/2007).

Houve, por exemplo, uma ocasião em que uma mulher, durante uma festa de Cosme e Damião no Templo de Umbanda Caboclo Trovão, foi pedir conselhos sobre como arrumar um namorado. A criança se recusou a conversar sobre o assunto, dizendo que era "coisa da tia baiana resolver". Essa situação ressalta essa característica de não lidar com questões da vida adulta, reforçando a sua associação ao infantil:

eles têm que cuidar de problemas de coisas que demandam mais amor, mais paciência, mais jeito... do que uma coisa que é bem da Terra, que é de dinheiro, que é de trabalho[...] (Médium do Terreiro de Umbanda Pai José do Rosário, 24/08/2007).

A relação da linha de Cosme e Damião com o sentimento de alegria é sempre retomada, sendo que eles parecem se aproximar dos adultos quando estes estão tristes ou doentes e, no geral, relacionam-se com crianças concretas

[...] é a gente vem... daí, po exempo, né, tia? Se ocê tá muito triste, nóis põe um fluidinho asiiiim e cê fica alegre! Daí se ocê tem um... um tio, uma mãe, uma palente, um qualqué um da sua família doente, e ocê pensa, cê pede pá nóis e nóis vamu lá: tiozinhoooo!!!! E ele vai e melora! Se ele, se ocê tive bastante fezinha! E daí se ocê também tive doente nóis também asuda! E nóis trabalha mais na linha do amor, pá leva amor pás pessoas! E pá ajuda tudo as cliancinha aqui da tela! (Marina, espírito infantil do Templo de Umbanda Caboclo Trovão, 05/02/2007).

Ficou evidente que a linha de Cosme e Damião também tem como um de seus principais usos rituais a proteção, que, segundo eles, não depende da crença da pessoa. Foi dito a um dos autores que, mesmo após a conclusão do trabalho de campo, mesmo que eles fossem esquecidos, eles sempre o acompanhariam, ainda que de longe, protegendo-o. Além disso, desde o primeiro contato com a linha, enfatizaram que cuidavam dele e o protegiam.

Quando você fô, quando você fô faze, assim faze, mostra né, você fô, assim pus pofessor, né? Qui os pofessor vai vê, a tamu nóis tudo lá tia, pá elis gosta, dá nota boa prucê (Sara, 05/02/2007).

Por último, essas entidades apareceram ainda como mensageiros e, tal como Birman (1985) encontrou, relacionam-se a um poder de limpeza particular. Segundo a chefa do Templo de Umbanda Caboclo Trovão: 
[...] às vezes a criança é necessária para fazer uma limpeza que nenhuma outra entidade é capaz, contam que o baiano Quebra Coco trabalha sempre com o Joãozinho (espírito infantil) do lado, tanto que sempre tem bala no seu ponto riscado. Eles trabalham juntos por esse poder de limpeza particular das crianças e o Joãozinho também faz um trabalho parecido com o de um mensageiro, pois quando o consulente vem pedir por alguém que não está presente é o Joãozinho que vai até a pessoa em questão e depois fala para o baiano o que está acontecendo.

Essa capacidade particular de limpeza pode ser associada à sensação de leveza e tranqüilidade relatada pelos adeptos como consequência da atuação dessas entidades e vivenciada no transcorrer da pesquisa.

\section{O INFANTIL E SUA REDE SIMBÓLICA}

$\mathrm{O}$ que mais apareceu em todas as narrativas obtidas nos terreiros a respeito da linha de Cosme e Damião, bem como nos rituais, foi o doce. Durante as giras, os doces são distribuídos para todos os participantes, são abençoados e levados para aqueles que não puderam comparecer na festa, principalmente, para auxiliar em questões ligadas à saúde.

Além disso, nesses casos os espíritos infantis costumam usar doce para "tratar" o local doente e proteger, passando-o sobre a pele da pessoa. Houve, por exemplo, uma ocasião no Templo de Umbanda Caboclo Trovão em que passaram brigadeiro na barriga de uma mulher grávida e pediram que não limpasse até o dia seguinte, pois estariam cuidando de seu bebê. E, mesmo nos rituais em que não há incorporação dos espíritos de crianças, há entidades que trabalham em conjunto com os erês, como o caso de um baiano, que coloca doces junto de seu "ponto riscado". ${ }^{2}$ Os médiuns lhes oferecem doces.

Essa oferenda, segundo narrativas dos espíritos, é importante para executarem seus "trabalhos". Além disso, conforme as entrevistas com os médiuns, o doce parece ser uma forma de comunicação com essas entidades, provavelmente também sendo uma espécie de "metáfora não verbal" da sua presença. É por meio do "doce" que elas se fazem reconhecidas quando não estão incorporadas. Por exemplo, foi relatado por alguns médiuns que quando sentem cheiro de bolo compreendem que esses espíritos estão por perto. Tem-se, portanto, o infantil principalmente ligado à questão gustativa, já que em suas giras o "comer" doce é fundamental. Segundo os espíritos, é a forma de eles levarem "estrelinhas" aos "tios".

Foi dito por uma médium do Templo de Umbanda Caboclo Trovão que, durante as preparações da festa de Cosme e Damião, ao realizar as compras para a festa era surpreendida com os doces preferidos das crianças "pulando" da prateleira para o chão. Dessa forma ela descobria o que era desejado por elas.

Outra forma dessas entidades se revelarem é por meio de flores. Alguns médiuns relataram sentir cheiro de flor quando os espíritos infantis estão por perto. 
Agora quando, pra incorpora ela eu sinto cheiro de rosas, sabe rosa quando você apanha assim, qualquer tipo de rosa cê mexe as pétala dá aquele cheirinho, eu sinto isso. (Madrinha do Templo de Umbanda Caboclo Trovão, 25/07/2007).

As flores também estão com frequência presentes nas narrativas dos espíritos de crianças. Contam que onde vivem é repleto de flores e jardins e que as utilizam para realizar "curas". Em um dos primeiros contatos com os espíritos infantis, um deles "receitou" que quando estivesse doente tomasse água com uma pétala de rosa cor-de-rosa e pensasse neles. Dessa forma seria curada:

"Eu goto di flor, tendeu? Cada um tem um jeito di trabalha, eu gosto da flor (entrevista com Sara a respeito de sua forma de trabalho, 05/02/2007).

Esse elemento está presente ainda em diversos pontos cantados que são utilizados durante os rituais, tais como

"Cosme e Damião a sua casa cheira

a cravos e rosas e a flor de laranjeira"

"Fui no jardim colher as rosas

e vovózinha deu-me as rosas mais formosas"

Nas narrativas das crianças espirituais, o jardim apareceu diversas vezes, seja ao descreverem o local onde vivem, seja ao especificarem a sua forma de trabalhar espiritualmente.

\author{
"Tem doce, meu pai \\ Tem doce, meu pai \\ Tem doce, lá no jardim" \\ (trecho de ponto cantado da Linha de Cosme e Damião)
}

Além disso, quando se pretende realizar uma oferenda de doces a essas entidades, o local mais indicado para fazê-la, segundo os adeptos, é um jardim florido.

[...] assim vamu, assim, eu pego, vo nu jardim, onde tem assim bastanta, ah... flor... mai não for cum epinhu, sem epinhu, num goto de for cum epinhu, num goto de for cum epinhu, então eu vô e pego as flor... vô lá... levo pó vô, levo pá vó, levo paquele tio paquela tia que tá no hospital, que tá fazendo tratamento, levo pa eles ficaa, pá eles ficaa, pá eles sara logoo, entendeu? (Sara, 05/02/2007).

Com relação aos jardins, segundo Bairrão (2003), diferentes culturas os associam a "elevados graus de realização espiritual", correspondendo à elevação atribuída aos espíritos infantis pelos adeptos nas suas narrativas. Além disso, para Jung $(1990,2000)$ o jardim, bem como a flor, pode se relacionar a lugar de nascimento, ou ainda ao self, ao círculo e à quaternidade e, conforme foi visto, o arquétipo do puer e a criança na umbanda também podem ser associados a esses símbolos da totalidade. 
Há ainda uma associação dessas entidades com as cores rosa e azul-claro, seja na forma de preparar o terreiro para as festas de Cosme e Damião, seja nos relatos dos espíritos, ou ainda em seus objetos, como por exemplo, o vestido corde-rosa que Marina, espírito infantil do Templo de Umbanda Caboclo Trovão, utiliza quando incorpora na sua médium:

\begin{abstract}
A matéria e o espírito da pessoa? Assim... ahn.... a pessoa tá... tá triste, tá tiiiste, tá chorosa... eu quero ela, quero vê ela feliz, então eu vô pega, uma for, cor-de-rosa, cor-derosa é sinal de alegria! É de felicidaaade! Então eu pego aquele, aquele fuido da... da da cor da for coor-de-rosa, transformo em remédio o fluido e levo pá pessoa que tá triste, tá certo tia? (Sara, 05/02/2007)
\end{abstract}

Por último, outro elemento que está presente com muita frequência nas giras das crianças é o brinquedo. Cada entidade possui seus brinquedos e também costumam cedê-los aos consulentes, que acabam interagindo com eles como se retornassem à infância.

Entre outros, aspectos sensoriais como o gosto doce, o cheiro de flor e a gestualidade do brincar parecem ser essenciais ao modo de a criança acontecer neste contexto. Na umbanda a idéia de espírito comporta acepções estético-sensoriais. Já na visão junguiana, tais associações podem ser explicadas pelo fato de o arquétipo se manifestar diferentemente em culturas diversas. Desta forma poder-se-ia dizer que a associação de cores e sabores ao infantil na umbanda seria resultado do contexto social em que ela se insere. No entanto, nada se encontrou em campo que permitisse inferir que no universo umbandista seja admissível uma separação entre forma e conteúdo e que os elementos sensíveis das suas práticas espirituais possam ser abstraídos ou relativizados.

Assim, apesar das aproximações do ponto de vista do seu conteúdo significativo, a identificação imediata das crianças da umbanda às manifestações arquetípicas é simplificadora e induz ao desconhecimento da originalidade das concepções etnopsicológicas umbandistas naquilo que elas possam apresentar de irredutível.

\title{
CONSIDERAÇões FINAIS
}

Este estudo possibilitou uma compreensão da categoria dos espíritos infantis na umbanda, suas principais características e elementos da sua rede simbólica. Caracterizada com uma das entidades principais do panteão umbandista, a criança é considerada um espírito puro que morreu precocemente. Em função disso, destaca-se ainda seu posicionamento elevado com relação aos demais espíritos. Seriam os mais próximos de Deus e nessa qualidade são por excelência os mensageiros do divino.

Dessa forma, possuem um poder de limpeza particular, proporcionando aos adeptos da umbanda alegria, leveza e tranquilidade. São responsáveis por lidar com questões sutis ligadas ao espírito, problemas de saúde ou atinentes a crianças. 
Revelam-se primordialmente por formas não verbais de comunicação e se mostram dirigindo-se diretamente ao eu e atendendo a necessidades daqueles a quem interpelam das quais, o mais das vezes, estes não estão cientes.

Os espíritos (no caso, os espíritos de crianças) são interlocutores sociais e sensíveis, isto é, apresentam-se como outro, comem, brincam e têm vontade própria. Tais características exigiram que o estudo não se restringisse a comparações entre símbolos. Fez-se necessário interagir com a manifestação desse tipo de experiência religiosa.

Do ponto de vista do conteúdo significativo, foram encontradas semelhanças entre sentidos veiculados pelos espíritos infantis e significados do arquétipo do puer. Assim como o puer, a criança na umbanda (os espíritos mais próximos de Deus) está associada ao self (que tem em Deus e na Criança Divina símbolos seus).

Mas a concepção de espírito e o modo como os espíritos infantis se mostraram no curso da pesquisa pressupõem concepções de mundo díspares que repercutem na compreensão da natureza última do infantil. Para a umbanda os aspectos estéticos e sensoriais associados ao infantil não são acessórios e não há uma oposição entre aspectos do (psiquismo) individual e um (inconsciente) coletivo genérico. Cada manifestação espiritual do infantil transcende a consciência individual, mas comporta uma certa individualidade, propondo-se como uma outra pessoa com uma história singular. A criança celestial da umbanda não se propõe como redutível a uma forma psíquica (arquétipo) genérica.

No entanto, a psicologia analítica se mostrou um modelo teórico comparativo bastante útil para orientar a pesquisa na direção do resgate e sistematização de uma compreensão etnopsicológica do infantil na umbanda.

\section{Notas}

${ }^{1} \mathrm{O}$ self seria o núcleo mais profundo e a totalidade absoluta da psique, um centro regulador responsável pelo desenvolvimento da personalidade - processo de individuação. Além disso, durante os sonhos, este núcleo pode ser personificado por diversas figuras, entre elas a de Cristo e a da criança (JUNG, 2002).

2 "Assinatura" ritual da entidade em geral feita no chão do terreiro com um giz especial chamado pemba.

\section{REFERÊNCIAS}

AUGRAS, M. Os gêmeos e a morte. Notas sobre os mitos dos Ibeji e dos Abikus na cultura afro-brasileira. In: PRANDI, R. As senhoras do pássaro da noite. São Paulo: Axis Mundi; Edusp, 1994. p. 73-84.

BAIRRÃO, J. F. M. H. Raízes da Jurema. Psicologia USP, São Paulo, v. 14, n. 1, p. 157-184, jan./mar. 2003. 
BAIRRÃO, J. F. M. H. Espiritualidade brasileira e clínica psicológica. In: ANGERAMI-CAMON, V. A. (Org.). Espiritualidade e prática clínica. São Paulo: Thomson, 2004. p. 193-294.

BIRMAN, P. O que é umbanda. São Paulo: Abril Cultural, 1985.

CAMPELO, M. M. Meu nome é Exu Mirim: imaginário e marginalidade social na umbanda. São Paulo: Terceira Margem, 2003.

CONCONE, M.H. V. B. Caboclos e pretos velhos na umbanda. In: PRANDI, R. Encantaria brasileira: o livro dos caboclos, mestres e encantados. Rio de Janeiro: Pallas, 2001. p. 281-303

FERNANDES, I. O arquétipo do malandro: Zé Pelintra como imagem do trickster nacional. Rubedo: Revista de Psicologia Jungiana e Cultura, Rio de Janeiro, ano 9, n. 35, out./dez. 2007. Disponível em: <http://www.rubedo.psc.br/artigosc/ pelintra.htm>. Acesso em: 2 out. 2008.

HILlMAN, J. Estudos de psicologia arquetípica. Rio de Janeiro: Achiamé, 1981.

HILlmAN, J. O livro do puer: ensaios sobre o arquétipo do Puer Aeternus. Tradução Gustavo Barcellos. São Paulo: Paulus, 1998.

HILLMAN, J. et al. Pais e mães: seis estudos sobre o fundamento arquetípico da psicologia da família. Tradução Pedro Penteado Kujawski. São Paulo: Símbolo, 1979.

JUNG, C. G. Psicologia e Alquimia. Tradução Maria Luiza Appy; Margaret Makray; Dora Mariana Ribeiro Ferreira da Silva. Petrópolis: Vozes, 1990.

JUNG, C. G. Os arquétipos e o inconsciente coletivo. Tradução Maria Luiza Appy; Dora Mariana R. Ferreira da Silva. Petrópolis: Vozes, 2000.

LAGES, S. R. C. Exu: o puer aeternus. Rubedo: Revista de Psicologia Junguiana e Cultura, Rio de Janeiro, ano 9, n. 35, out./dez. 2007. Disponível em: <http:// www.rubedo.psc.br/artigosb/exusonia.htm>. Acesso em: 21 fev. 2008.

LIMA, B. Malungo: decodificação da umbanda. Rio de Janeiro: Bertrand Brasil, 1997.

LUTZ, C. Ethnopsychology compared to what? Explaining behavior and consciousness among the Ifaluk. In: WHITE, G. M.; KIRKPATRICK, J. Person, self, and experience: exploring pacific ethnopsychology. London: University of California, 1985. p. 35-79. 
SEGATO, R. L. Santos e daimones: o politeísmo afro-brasileiro e tradição arquetipal. Brasília: UNB, 1995.

SILVA, P. R. Exu/Obaluaiê e o arquétipo do médico ferido na transferência. In: MOURA, C. E. M. (Org.). Candomblé - religião do corpo e da alma: tipos psicológicos nas religiões afro-brasileiras. Rio de Janeiro: Pallas, 2000. p. 165196.

VON FRANZ, M. L. V. Puer aeternus: a luta do adulto contra o paraíso da infância. Tradução Jane Maria Corrêa. São Paulo: Paulus, 1992.

ZACHARIAS, J. J. M. Ori Axé: a dimensão arquetípica dos orixás. São Paulo: Vetor, 1998.

Recebido em: abril de 2009

Aceito em: agosto de 2009 